\title{
P-5
}

\section{BCR Sequential Extraction and AAS Analysis of Selected Heavy Metals in Street Sediments of Some Cities of Heavy Motor Traffic and Industrialization in Sri Lanka}

\author{
Fernando W.R.A.* and Karunarathne P.K.D.M.C. \\ Department of Chemistry, Faculty of Applied Sciences, University of Sri Jayewardenepura, \\ Nugegoda, Sri Lanka \\ *rashmiamani@gmail.com
}

\begin{abstract}
Topsoil and street-deposited sediments in urban areas are sinks for potentially toxic metals. Heavy metals are considered as serious inorganic pollutants due to their toxic effects on living organisms having a high accumulation and slow removal rate. Vehicle emissions, industrial discharges and other anthropogeni c activities are the sources of heavy metals such as cadmium $(\mathrm{Cd})$, lead $(\mathrm{Pb})$, chromium $(\mathrm{Cr})$, cobalt $(\mathrm{Co})$, nickel $(\mathrm{Ni})$, copper $(\mathrm{Cu})$, and zinc $(\mathrm{Zn})$ in roadside sediments in urban areas. Though the common practice is to report the total metal content of polluted soil sample, it does not accurately reflect the metal mobility in the environment, bioavailability or the level of environmental hazard of the metal. Conversely, modified BCR (European Community Bureau of Reference) sequential extraction procedure permits the fractionation of heavy metals based on the chemical association of different metal pollutants in soil.
\end{abstract}

In this study, street surface sediment and dust deposition on roadside tree leaves were collected from Pettah, Borella, Nugegoda, Katunayake, and Makandura areas and sediments of a vehicle washing station at Negombo was also collected. According to the BCR procedure, four fractions (water and acid soluble, reducible, oxidisable, residual) were separated from each sample and analysed by flame atomic absorption spectroscopy (FAAS) using standard addition method. Metal contents in total extracts were also analysed by FAAS and compared with the total sum of four BCR fractions obtained for each metal ion.

The total mean contents of $\mathrm{Pb}, \mathrm{Cr}, \mathrm{Ni}, \mathrm{Cu}$, and $\mathrm{Zn}$ were calculated for each fraction for all six locations. Heavy metals, $\mathrm{Cd}$ and Co were not detected. Out of five heavy metals under investigation, only $\mathrm{Cr}$ in the bioavailable or potentially bio available fraction exceeded the recommended level that caused risks on human health, according to the New York state department of environmental conservation (NYS DEC 2007). Significant levels of $\mathrm{Ni}$ and $\mathrm{Pb}$ were detected in the sediment samples from Nugegoda and Katunayake, Nugegoda and vehicle washing station at Negombo, respectively. Through continuous industrialization and heavy motor traffic, both $\mathrm{Ni}$ and $\mathrm{Pb}$ contents in these locations could soon surpass the levels of unrestricted residential use recommended by NYS DEC 2007.

Keywords: Street sediments, BCR Sequential extraction, Heavy metals, AAS

Proceedings of the International Forestry and Environment Symposium 2013 of the Department of Forestry and Environmental Science, University of Sri Jayewardenepura, Sri Lanka. 